\title{
A Model to Manage Crude Palm Oil Production System
}

\author{
John Inyang ${ }^{1 *}$, Magdalene Andrew-Munot ${ }^{1}$, Syed Tarmizi Syed Shazali ${ }^{1}$, Shirley Johnathan Tanjong ${ }^{1}$ \\ ${ }^{1}$ Department of Mechanical and Manufacturing Engineering, Faculty of Mechanical Engineering, Universiti Malaysia Sarawak, 94300 \\ Kota Samarahan, Sarawak, Malaysia.
}

\begin{abstract}
.
This paper reviews key production process for crude palm oil and highlights factors that highly influence the production of crude palm oil. This paper proposes a generic conceptual model for crude palm production process considering these factors. The conceptual model could be modified to consider other factors not included in this paper. The future research would be to construct a simulation model based on the conceptual model proposed in this paper and analyse the effect of these factors on the performance of crude palm oil production system.
\end{abstract}

\section{INTRODUCTION}

Malaysia is the second largest palm oil producer in the world [1]. It is important to the socio- economy growth of the country. In Malaysia, the governments emphasize that oil palm is important source of elements for the economic growth and developments. This can be seen when government formed the Federal Land Development Authority (FELDA) which functionally to help low incomes background families [2]. The Malaysian palm oil industry is expected to provide alternative fuel which can used to decrease the depletion rate of non-renewable fossil fuels. Palm oil is versatile as the oil is rich in antioxidants and low cholesterol level. Palm oil is normally used in food product such as ingredient in cooking oil, margarine and vegetable oils. Palm kernel is usually used in production of soap, shampoo and detergent.

The palm oil fresh fruit bunch can weigh up to around $50 \mathrm{~kg}$ and must be processed immediately within 48 hours to keep the freshness of the fruit [3]. Crude palm oil (CPO) is obtained from crushing the mesocarp and the by-product is palm kernel. Generally, crude palm oil production involves fresh fruit bunch reception processes which are FFB weighing, grading, cages loading, sterilisation, tipping and threshing, digestion, pressing, clarification and kernel extraction and drying process. Similar to production process of other products, palm oil production processes are highly affected by several factors that include the shortage of FFB, the aging of palm oil, labour shortage; replanting and seasonal constraints also affected the crude palm oil production [4]. No continuous on-line monitoring also affects the crude palm oil production [5]. CPO production in Malaysia is also affected by rainfall, increase in matured areas, fertiliser applications and replanting programmes [6]. Apart from that, palm oil yield in the plant is primarily determined by biological factors such as crop genetics and the incidence of pests and diseases [7]. In addition, crop that the estate sends to the mill more than two days old are potentially high in free fatty acid (FFA) which will directly affect the daily crude palm oil production [8]. Thus, the significance factors such as capital, labour and utilisation rate in the production of Crude palm oil (CPO) also contribute to the growth of palm oil production sector in Malaysia [16]. Hence, Indonesia also shows that the Crude palm oil commodity is one of the main commodities to contribute to foreign exchange earnings from exports in global market [17]. Indonesia also faced some problems in the palm oil industry include the low productivity of fresh fruit bunches, the limited industrial downstream, policies that are not conducive and the lack of palm oil fruit processing plant [18]. Crude palm oil (CPO) is highly depending on FFB coming into the mill. The mill cannot produce good quality of oil without any good raw material such as fresh fruit bunch (FFB) [19].

This paper proposes a generic conceptual model for crude palm oil production process. This generic conceptual model is developed taking into consideration the key production processes for crude palm oil and the presence of factors that highly affect this production processes. This paper is organised as follows. The next section discusses the crude palm oil production process. Then a generic conceptual model for crude palm oil production process is proposed. Finally, this paper ends with conclusion.

\footnotetext{
Corresponding author: johninyang0210@gmail.com
} 


\section{CRUDE PALM OIL PRODUCTION} PROCESS

Figure 1 shows a crude palm oil production process formulated based on the processes described in [4-5], and [8-11]. As shown in Figure 1, the CPO production process involves fresh fruit bunch(FFB) reception, FFB weighing, grading, cages loading, sterilisation, tipping and threshing, digestion, pressing, clarification and kernel extraction and drying.

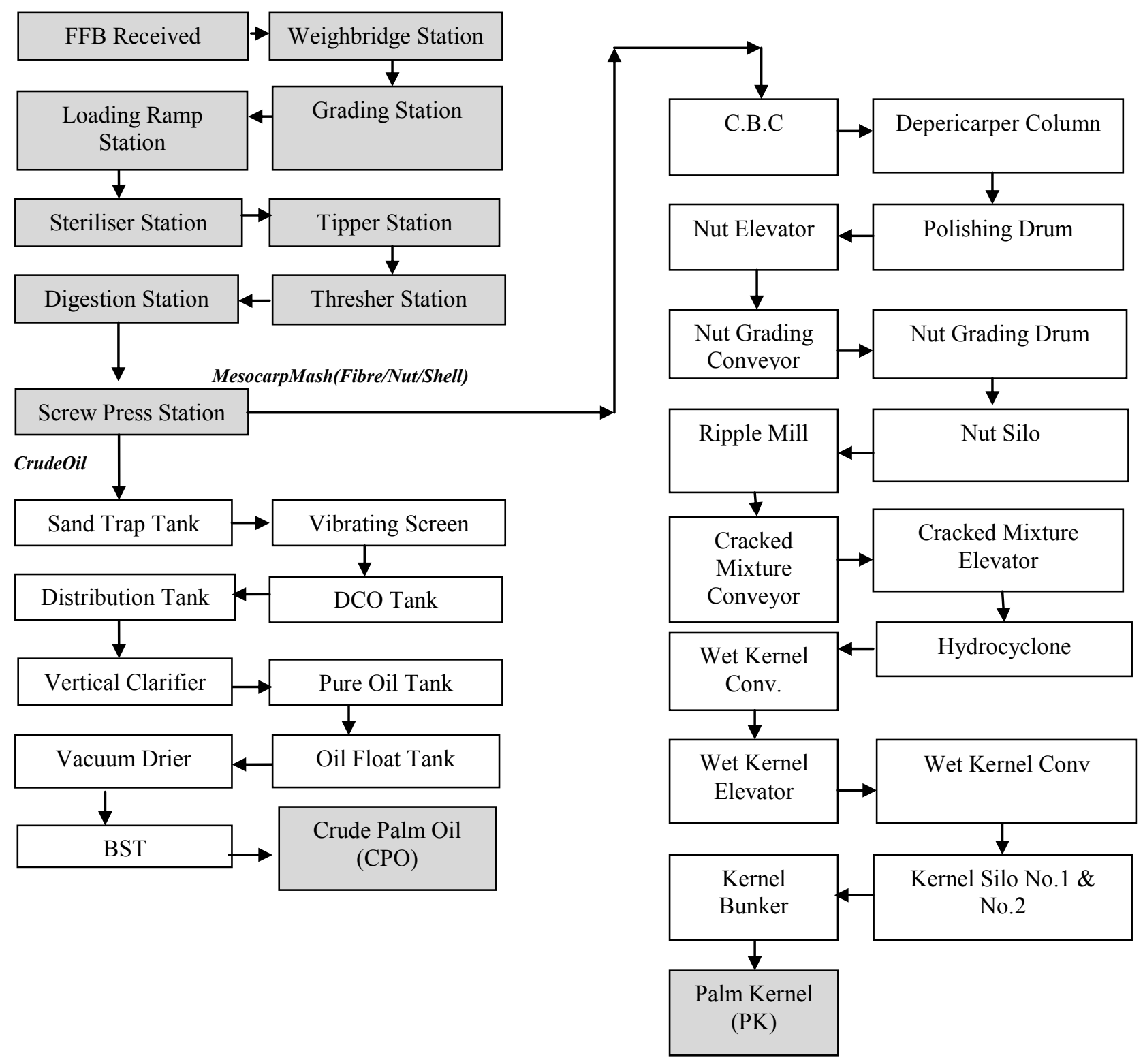

Figure 1: A generic crude palm oil production process developed based on the processes described in [4-5] and [8-11] 


\section{Fresh Fruit Bunch (FFB)}

Generally, fresh fruit bunch (FFB) can be obtained from the mill's own estate or other estates. The estate plays important role to supply the FFB to the mill. Shortage of FFB can affect the processing hours and the company performance [4]. Thus, sufficient supply of FFB to the mill will increase the mill's oil extraction rate and kernel extraction rate. The quantity of FFB is not the major measurement that mill should look upon. The quality of FFB should be maintained so that the mill can produce lower free fatty acid crude palm oil product. The mill will meet the capacity if there is a huge number of increment in FFB supplied [9]. Thus, the estate needs to ensure that the quantity and quality of FFB supplied to the mill are sufficient.

\subsection{Process 1: Fresh Fruit Bunch (FFB) Reception}

The first process begins with fresh fruit bunch (FFB) being transported from the estate to the mill [4,5].Incoming fresh fruit bunch are weighed at the weighbridge station. These FFB received in the mill will go through several stages before being processed into final product such as crude palm oil (CPO) and palm kernel(PK). The first factor that affects FFB reception is usually the estate being late in sending the crop to the mill. Apart from that, rainy day also cause delay in sending the FFB to the mill. For example, the estate will face difficulty to harvest the crop when it is raining in the morning. It's important to ensure the delivery of fresh fruit bunch to the mill is on time to maintain the FFB freshness [8]. At plantation level, the manager or mill's owner need to comply with the estate's request even though there are problems such as aging palm oil, labour shortages, and replanting [4]. Estate that undergoes replanting will face difficulty to send higher number of crop to the mill. This is due to the crop itself is not completely in ripe mode to be harvested.

\subsection{Process 2: FFB Weighing}

Fresh fruit bunch that are received will go through weighing process. This time, the weighbridge attendant plays an important role to record the actual weight of the crop. The weighbridge attendant should identify the crops that are coming from which estate during the crop weighing process [8]. During this process, the weight variance should be within the daily range. This is to ensure that the weight of FFB is not over the limit of 60 tonne during weighing process. The weighbridge physical condition also contributes to the problem related to weighing. For example, misalignment of the weighbridge seal will affect the reading of the FFB crop weight. Apart from that, the weighbridge system might not be updated correctly by the attendant during FFB weighing process. This will affect reading for the number of daily FFB received at the mill.

\subsection{Process 3: FFB Grading}

Next the FFB are graded and inspected before being loaded into the ramp [9]. The grader will grade the FFB randomly at grading ramp surface area. For any consignment that is below 5 tonnes, the minimum number of FFB sample to be graded is 50 , whereas for consignment that is above 5 tonnes, the minimum samples of FFB to graded is 100 [12]. During the grading activity, it is important to ensure that the FFB are placed in dry area. Initially, the grader will do "moping" with the consignment that available at the grading station. This is to ensure the grader randomly take out any unripe sample from the consignments. During the moping process, the grader might face difficulty when they can't identify the FFB quality. Apart from that, the FFB size also will affect the FFB grading process. Since the FFB come with different size, the grader will take time to arrange the FFB sample. The weight of each sample itself is hard to arrange properly during grading time. Manual handling using spear to take out the FFB sample from the consignments also affects the daily FFB grading process. Grader will get tired and injured easily since the FFB grading is $100 \%$ done by manpower.

\subsection{Process 4: FFB Cages Loading}

FFB will be loaded into empty cages at the cages loading ramp before undergoing the steam - sterilization process [4]. For one single cage, the load limit is 7.5 tonne when the cage is fully load with FFB [8]. Cages are used to transfer the fresh fruit bunch into the steriliser line and the crane is also used to lift the cages and pour the fruit bunches into the hopper [9]. For Belaga Palm Oil Mill, wire rope is used to pull the cages and loading it with the FFB before transfer the cages to the steriliser station. There are few weaknesses when using the wire rope to pull the cages. For example, the wire rope can easily get cut during pulling and pushing the cages. Also the number of cages that can be pulled when using the wire rope is limited to 5 cages only. The life span of wire rope would be shorter when the worker uses it to pull more than 5 cages at one time. The number of operators at the loading ramp station also affects the loading process of FFB into the cages. There will be time delay when there is no worker available at the loading station since the cages loading process is partially carried out by the operators.

\subsection{Process 5: FFB Sterilization}

From the loading ramp station, the cages loaded with FFB will be transferred to the sterilization station. The pressure vessel used for cooking the FFB with steam is known as the steriliser and the process is known as sterilisation [13]. The steam-sterilization process facilitates the separation of the fruit lets from the bunch body [4].The fruit bunches that go through the steam sterilised will be easily detached from the stalk [5]. At this stage, the operator should maintain the pressure 
supply to the steriliser. During sterilisation, heat must be allowed to penetrate into the pericarp and high enough temperature for a long period of time. Low steam pressure supply into the steriliser will prevent the fruit from completely detaching from the bunch. This will contribute to the mill loses such as low oil extraction rate (OER) and kernel extraction rate (KER) at the end of the day. Air supply by the compressor at this station also needs to be monitored continuously by the operator. Pneumatic valve will difficult to open and closed when the air supply by the compressor is low. This will affect the steriliser system during operations. The sterilising mode also plays an important role at this stage; the holding time will be different for different sterilising mode. For example, the unripe mode has holding time of 40 minutes whereas the overripe mode has holding time of 20 minutes [8].

\subsection{Process 6: FFB Tipping and Threshing}

From the steriliser station, the sterilised FFB will be transferred to the tipper and threshing station. Tipper is used to tip the sterilised FFB into the mechanical bunch feeder. At the tipper station, cages are slowly tip and the sterilised bunch will fall into the hydraulic door before it transfers to the mechanical bunch feeder. The tipping time is important to maintain the mill throughput. Operators and supervisor should ensure that there is no delay during tipping. Cages that are stuck during the operation also effect the daily milling hours. The operator should handle the cages carefully to avoid any trouble during processing time. The thresher can be described as a large diameter rotating drum. During threshing the sterilised FFB are fed in continuously at ones end and stalks pass out continuously at the other end. BPOM used thresher drum with shaft and chain feeder type. During threshing, any sterilized bunch that comes in bigger size will get stuck inside the conveyor. This will cause the whole system stop during operation. Thus, to prevent any delay during tipping, the cages must be handled with care and fast actions are required when the sterilized bunch is stuck inside the conveyor.

\subsection{Process 7: FFB Digestion}

Next the sterilised fruit reach the digester station. The digester machine is used to rupture all the oil bearing cells and loosen the pericarp from the nuts. Apart from that, the digester machine is used to separate the fibres from its nut and to extract the oil from fruit lets [9]. Fruits that are detached are further softened with steam inside the digester [5]. Thus steam supply inside the digester machine should be maintained by the operator. This is to prevent the fruit inside the digester completely blend during operation. This process will be affected when the steam supply into the digester is low. Thus, the operator should maintain the digester to be fully loaded with sterilised fruit during the operation. This is to ensure that the mill is not achieving low throughput at the end of the days. The time to replace the blade inside the digester is also important. The proper blade used during the operation is important to ensure that the pericarp is completely loosened from the nut.

\subsection{Process 8: FFB Pressing}

Next, the fruit lets are moved to a pressing station where the palm oil is extracted [4]. At this stage, screw press is used to press the digested fruit to extract the oil contained in the mesocarp. Crude oil and fibre mix with nut, shell and kernel are produced during the pressing process. Next, the crude oil will go through the vibrating screen process to sieve the sludge from the crude oil [9]. It is important to ensure that the press cages physical conditions are not block by the mesocarp mash. The moisture of the mesocarp mash also needs to be considered to prevent the oil losses at this stage. Thus, the broken nut efficiency also needs to be maintained to prevent the kernel losses at this stage.

\subsection{Process 9: Clarification Process}

The clarification process removes moisture, solids and impurities [4]. Crude oil is transferred into the vertical clarifier tank and store to allow sediment process to obtain clarified oil [9]. Pure oil are then stored into the pure oil tank and purified before entering the oil storage tank. The underflow from the lower section of the clarification tank is centrifuged to remove as much of the heavier phase that constitutes oil loss as it is discharged as effluent. The lighter phase from the centrifuge which consists of oil and water is recycled to the clarification tank [5]. It is important to ensure that, the hot water supply into the tank is within the temperature range. This is to prevent the oil become clot during operation. High and low free fatty acids (FFA) quality should be monitored during the operation. The operator should know and be alert for every hour of the FFA production. The operator must have a clear decision which tank the oil should be stored when there is high and low FFA produced. Apart from that, the valve handling at clarification station should be taking care during operation. At the ends of processing times, operator should inspect the valve install. The operator plays an important role to ensure crude palm oil produce is skimmed and further purified, dried and sold as CPO.

\subsection{Process 10: Kernel Extraction and Drying}

The final stage would be separating the fibres, nuts and small portions of the kernel and shell to get kernel as another from the mill. Before storing the kernel must be dried completely to prevent fungus from developing. The finish kernel is stored inside the kernel bunker [9].The cracking efficiency during process also affected the kernel extraction rate (KER) production. 


\section{Crude Palm Oil}

The crude palm oil fulfils the demand of refiners and palm-oil based products manufacture [4]. The quality of the crude palm oil produce is affected by the quality of FFB received [8]. Also, the quantity of the crude palm oil produced is affected by the number of fresh fruit bunch, number of tipper machine and number of worker at loading ramp is affected the crude palm oil production.

\section{Palm Kernel}

The palm kernel (PK) is one of the final products produced from the palm oil mill. The quality of the palm kernel produce is affected by the quality of FFB received [8]. Apart from that, the cracking efficiency during cracking process also affected the palm kernel production. The palm kernel is generally extracting the oil outside the mills that process other oilseeds such as groundnuts, rapeseed, cottonseed, and copra [14].

\section{PROPOSED GENERIC CONCEPTUAL MODEL}

As discussed earlier the CPO production involves FFB reception, FFB weighing, grading, cages loading, sterilisation, tipping and threshing, digestion, pressing, clarification and kernel extraction and drying process. The discussions on key processes also highlights several factors that affect the CPO production which include (1) delay delivery of FFB to the mill, (2) rain that delay the delivery of crop process, (3) aging palm oil, labour shortage and replanting, (4) weight variance, (5) weighbridge physical condition (6) incorrect weighbridge update, (7) unidentified FFB quality, (8) different size of the FBB, (9) manually handling of the FFB sample during FFB grading, (10) usage of wire rope, (11) limited number of cages to be pull during loading cages process, (12) life span of wire rope, (13) number of workers available at loading station, (14) low steam pressure supply at FFB sterilisation process , (15) low air pressure supply at sterilisation process, (16) different mode of sterilisation, (17) tipping time, (18) cages stuck during operation, (19) number of tipper machine (20) steam supply to the digester machine, (21) digester load, (22) number of digester machine, (23) number of pressing machine, (24) moisture of mesocarp mash, (25) broken nut efficiency, (26) hot water supply, (27) FFA quality, (28) valve handling, (29) kernel moisture, and (30) cracking efficiency during PK production

Similar to the production process of any other products, it is important to consider these factors that affect the $\mathrm{CPO}$ production process in order to improve the performance of any CPO production system. Therefore, this paper proposes a generic conceptual model (Figure 2) for CPO production process. The generic conceptual model is characterized by ten (10) key processes together with affecting factors. Each key process is affected by several factors which in turn affect the next key process and ultimately would affect the performance of crude palm oil production process. Ultimately, it's important to identify the factors affecting each process to ensure smooth production of crude palm oil and palm kernel and hence maintain competitiveness. The generic conceptual model could be further modified to include any other factors that may affect the CPO production. Furthermore, this generic conceptual model could become an important decision-making support tool for the industry as well as the academicians. 
(1) delay delivery of crop to the mill (2) rain that delay the delivery of crop process (3) aging palm oil, labour shortage and replanting

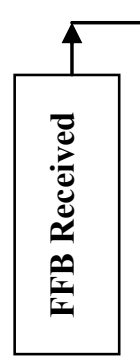

(4) weight variance

(5)weighbridge physical condition

(6)incorrect weighbridge update

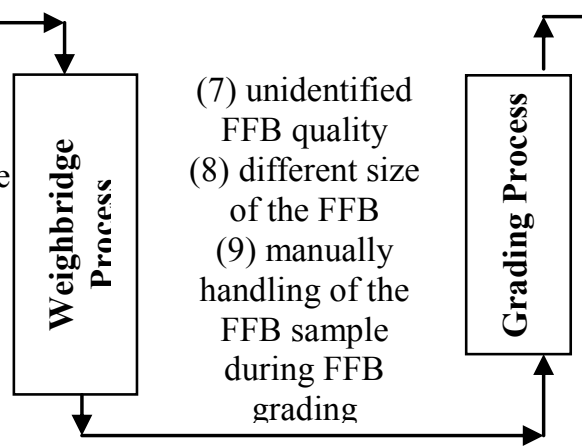

(10)usage of wire rope

(11)limited number of cages to being pull

(12) life span of wire rope (13) number of workers available at loading station

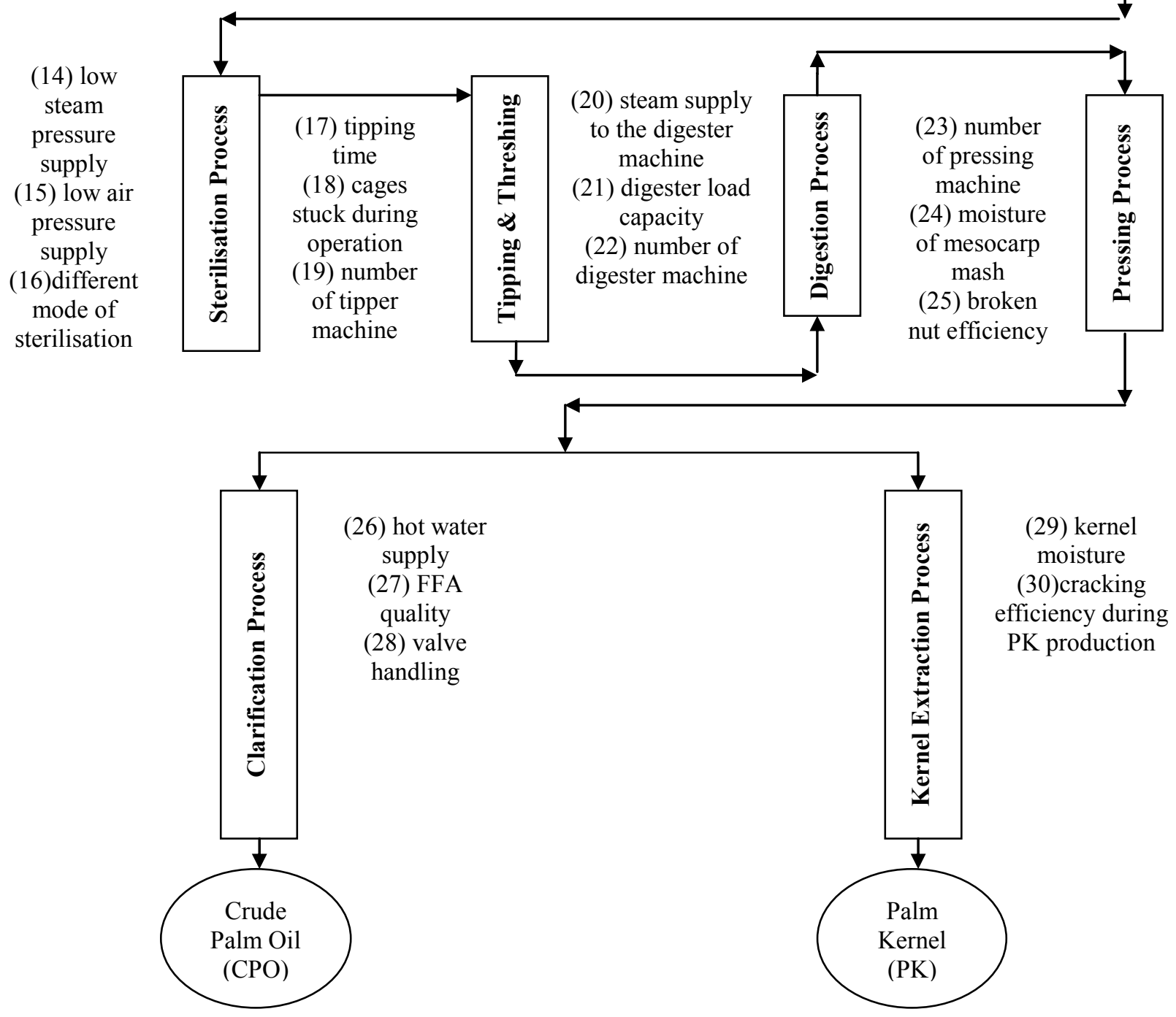

Figure 2: Proposed generic conceptual model for crude palm oil production with affecting factors [4-5] and [8-11] 


\section{CONCLUSIONS}

In Malaysia, Palm Oil has made impressive and sustained growth in the global market among the 17 world major oil and fats industry [15]. This progress has been primarily motivated by emerging factors such economic growth and development, to help low-income background family and to provide alternative fuels in future. For Malaysia, palm oil has the highest average productivity compared to other major crops, and become one of the efficient producers of oil among the oil crops [20]. This paper has highlighted the key production process for crude palm oil production and proposed a conceptual model that considers the presence of factors that highly affect this production. The model could be further modified to into account any other factors that might affect the crude palm oil production process. The generic conceptual model for CPO production could become a valuable decision-making support tool. Therefore, the future direction of this research work is to construct a simulation model based on the generic conceptual model and analyse the effect of these factors on the performance of CPO production.

\section{ACKNOWLEDGMENT}

This work is part of a master project on Crude Palm Oil Production System for postgraduate student.

\section{REFERENCES}

[1] Abdullah R, An analysis of crude palm oil production in Malaysia (n.d)

[2] Kenneth R. Szulczyk, The Economic of the Malaysian Palm Oil Industry and Its Biodiesel Potential, (2013)

[3] Bogota,Background Document An overview of the palm oil sector, countries and companies. Global Palm Oil Conference.(2015)

[4] Mohamad Fazeeda, Mat Tahar, R. Measuring palm oil mill capacity usingmodelling and. Measuring Palm Oil Mill Capacity Using Modelling andSimulation, 1, (2010)

[5] Chow, MC,Ho, C C,Surface Active Properties of Palm Oil With Respect To The Processing Of Palm Oil,12 No.1, p.107.116,(2000)

[6] Abdullah, R. An Analysis of Crude Palm Oil Production in Malaysia,36-43.(2012)

[7] Murphy, D. J, The future of oil palm as a major global crop: opportunities and challenges,1-24, (2014)

[8] Saravanan, S. (2018, March 15). Personal interview.

[9] Mohamad, F, Tahar, M, \& Awang, N. (n.d.). Evaluating capacity of palm oil millusing simulation towards effective supply chain - a case study, (n.d)

[10] Vijaya, S, MA, A.N, Choo, Y.M and Nik Merian, N.S, Life cycle inventory of the production of crude palm oil-A gate to gate case study of 12 palm oil mills,20, p.484-494, (2008)
[11] Vijaya Subramaniam, Choo Yuen May, Halimah Muhammad, Zulkifli Hashim, Yew Ai Tan,and Puah Chiew Wei, Life Cycle Assessment of the production of crude palm oil (part 3), 22, p895-903, (2010)

[12] Manual Penggredan Buah Kelapa Sawit $M P O B, \mathbf{3},(2015)$.

[13] Hassan, Basiron, Sukaimi, Hung, Salleh and Basri,,Palm Oil Factory Process Handbook Part 1, (n.d) [14] Palm Oil Processing, (n.d). Retrieved from http://www.fao.org/docrep/005/Y4355E/y4355e04.htm

[15] Chong Chee Guan. Syed Amear ,Syed Ariffin, Alison McKay, Environmental Sustainability Drivers: A Study On Malaysian Pam Oil Industry. (2016)

[16] Norhidayu A, Nur Syazmani M, Radzil, Amin and Balu N, The Production of Crude Palm Oil in Malaysia, (2017).

[17] Imamudin Y, The Roles Of Crude Palm Oil (CPO) Commodities in Indonesian Economy Granger Causality Analysis Approach, (2018).

[18] Suryani E, Hendrawan R, Muhandhis I, and Dewi L, Dynamic Simulation Model of Crude Palm Oil Supply Chain to Determine Fulfillment Ratio and Manufacturing Efficiency of Cooking Oil Industry, (2018).

[19] Noviar M, Sukardi and Riffin A, Quality Control System of Crude Palm Oil on Palm Processing Industry (Case Study Bah Jambi Palm Oil Mill, PTPN IV, Medan, North Sumatra), (2016).

[20] Abdullah R, and Wahid M, World Palm Oil Supply, Demand, Price and Prospects ; Focus On Malaysian and Indonesion Palm Oil Industry,(n.d) 